\title{
Materialidades afectantes, memorias reflexivas y ensayos performáticos. Movilización de saberes encarnados en la universidad ${ }^{*}$
}

\author{
Silvia Citro \\ Universidad de Buenos Aires, Conicet, Buenos Aires, Argentina \\ scitro_ar@yahoo.com.ar \\ https://orcid.org/0000-0002-4597-3733 \\ Manuela Rodríguez \\ Universidad Nacional de Rosario, Conicet, Rosario, Argentina \\ manuela.guez@gmail.com
}

\section{RESUMEN}

Como investigadoras y docentes universitarias, nos interesa indagar sobre la capacidad de agencia y reflexividad que deviene de nuestras corporalidades. Así, ensayamos metodologías transdisciplinares de performance-investigación, basadas en la exploración performática y la reflexividad sociocrítica. En primer lugar, realizamos una reseña crítica de los patrones ontológicos, epistémicos y políticos de la modernidad/colonialidad que llevaron a invisibilizar y silenciar las corporalidades sensibles y en movimiento en las ciencias sociales y humanas. Luego, analizamos las principales propuestas didácticas de performance-investigación que hemos desplegado: a) la indagación desde las materialidades afectantes pro-

vocadoras; b) el ejercicio de la memoria encarnada y la reflexividad analítica sobre las propias experiencias vividas y genealogías; y c) los ensayos performáticos colectivos del imaginar-desear. Nuestra hipótesis es que la apertura a ensayar articulaciones situadas y críticas de estas diversas modalidades posee un peculiar potencial para movilizar procesos de reflexión sobre los saberes encarnados, así como micropolíticas de agenciamiento que propicien su transformación y expansión hacia un horizonte decolonial.

Palabras clave: prácticas educativas; corporalidad; materialidades afectantes; performances; micropolíticas; agenciamientos.

Cómo citar: Citro, S. y Rodríguez, M. (2020). Materialidades afectantes, memorias reflexivas y ensayos performáticos. Movilización de saberes encarnados en la universidad. Ciencias Sociales y Educación, 9(17), 23-56. https://doi.org/10.22395/csye.v9n17a2

Remitido: 3 de diciembre de 2019.

Aprobado: 2 de marzo de 2020. 


\section{Affective Materialities, the Reflective Memories and Performance Explopations. Mobilization of Knowledge(s) Incarnated in the University}

\section{ABSTRACT}

As researchers and university teachers, we are interested in inquiring upon the capacity for agency and reflection that becomes from our corporealities. Thus, we explored transdisciplinary methodological exercises of a performance-research type, based on the performative exploration and the socio-critical reflection. In the first place, we critically reviewed the ontological, epistemic, and political patterns of coloniality/ modernity that led to the invisibilization and silencing of sensory corporealities in movement with the social and human sciences. Then, we analyzed the main didactic proposals of the performance-research type deployed so far: a) an inquiring from provocative affective materialities; b) the exercise of incarnated memory and analytical reflection about the own life experiences and genealogies; and c) the collective performative explorations of imagining and desiring. We hypothesize that the aperture to exercise and try out new and critically located articulations of diverse modalities has particular potential for mobilizing reflective processes about the incarnated knowledge(s) as well as the micro-policies of agency that promotes its transformation and expansions towards a decolonized horizon.

Keywords: educational practices; corporeality; affective materialities; performances; micro-policies; agency.

\section{Materialidades afetantes, memórias reflexivas e ensaios performáticos. Mobilização de saberes encarnados na universidade}

\section{RESUMO}

Como pesquisadoras e docentes universitárias, é do nosso interesse indagar sobre a capacidade de agência e reflexividade que advém de nossas corporeidades. Assim, ensaiamos metodologias transdisciplinares de performance-pesquisa, baseadas na exploração performática e na reflexividade sociocrítica. Em primeiro lugar, realizamos uma resenha crítica dos padrões ontológicos, epistêmicos e políticos da modernidade/colonialidade que levaram a invisibilizar e silenciar as corporeidades sensíveis e em movimento nas Ciências Sociais e Humanas. Logo, analisamos as principais propostas didáticas de performance-pesquisa que desenvolvemos: a) a indagação a partir das materialidades afetantes provocadoras; b) o exercício da memória encarnada e a reflexividade analítica sobre as próprias experiências vividas e genealogias, e c) os ensaios performáticos coletivos do imaginar-desejar. Levantamos a hipótese de que a abertura a ensaiar articulações situadas e críticas dessas diversas modalidades tenha um peculiar potencial para mobilizar processos de reflexão sobre os saberes encarnados, bem como micropolíticas de agenciamento que promovam sua transformação e expansão por um horizonte decolonial.

Palavras-chave: práticas educativas; corporeidade; materialidades afetantes; performances; micropolíticas; agenciamentos. 


\section{Introducción}

Como equipos interdisciplinario ${ }^{1}$ dedicados a la docencia universitaria y a la investigación, desde hace veinte años venimos trabajando tanto en el campo de las ciencias sociales y humanas como en el de las artes de la performance en universidades de Argentina y otros países de América Latina. Nos hemos focalizado en la pregunta sobre la capacidad de agencia y reflexividad que deviene de nuestras corporalidades. Así, en nuestra labor de enseñanza en ciencias sociales y humanas fuimos apreciando cómo predominaba la tendencia a invisibilizar y silenciar el potencial de las corporalidades sensibles y en movimiento, como una de las herencias del logocentrismo de la modernidad/ colonialidad. Pero también en la formación en determinadas artes (en especial música, danza clásica y contemporánea, artes plásticas) se tiende a invisibilizar y silenciar la reflexión sobre la diversidad sociocultural de las prácticas estéticas de cada región, en pos de un modelo de tecnificación artística de los cuerpos, heredero de la modernidad/colonialidad. Esta reflexión nos llevó a ensayar, desde 2012, metodologías alternativas de carácter transdisciplinar que hoy denominamos "performance-investigación", basadas tanto en la exploración performática como en la reflexividad sociocrítica. Como veremos, estas propuestas se enmarcan en un horizonte decolonial que aboga, especialmente, por una interculturalidad crítica. En este sentido, es importante situar que nuestro decir-hacer-pensar como docentes hoy se halla inextricablemente unido a dos caminos que también recorrimos: como performers en los ámbitos de la danza, la teatralidad y la música, y como investigadoras antropólogas, especialmente en los trabajos de campo. El trabajo de Silvia se ha centrado en las prácticas culturales de los pueblos originarios y el de Manuela en las prácticas de los afrodescendientes.

En la primera parte de esta presentación realizaremos una breve reseña acerca de los caminos que nos condujeron hacia la performance-investigación a partir de la crítica a los patrones ontológicos, epistémicos y políticos de la modernidad/colonialidad. En la segunda parte, a través de la sistematización de nuestras prácticas educativas en la universidad, describiremos las principales propuestas de performance-investigación que hemos identificado: a) la indagación desde las materialidades afectantes provocadoras; b) el ejercicio de la memoria encarnada y la reflexividad analítica sobre las propias experiencias vividas y genealogías; y c) los ensayos performáticos colectivos del imaginardesear. Asimismo, analizaremos sus diferentes antecedentes y resonancias

Equipo de Antropología del Cuerpo y la Performance (Facultad de Filosofía y Letras, Universidad de Buenos Aires) y área de Antropología del Cuerpo (Facultad de Humanidades y Artes, Universidad Nacional de Rosario). 
performativas en los y las estudiantes ${ }^{2}$, retomando tanto sus narrativas como nuestros registros etnográficos de las clases.

Nuestra hipótesis es que la apertura a ensayar articulaciones situadas y críticas de estas diversas modalidades pedagógicas que involucran el trabajo colectivo desde las corporalidades y materialidades sensibles y en movimiento, posee un peculiar potencial para movilizar procesos de reflexión sobre los saberes encarnados, así como micropolíticas de agenciamiento que propicien su transformación y expansión hacia un horizonte decolonial.

Finalmente, deseamos aclarar que, si bien como coordinadoras de estos equipos hemos asumido la tarea de dar un formato escrito final a estas sistematizaciones y análisis, estas son inseparables del trabajo colectivo y, por tanto, de las colaboraciones puntuales de sus diversos miembros. Entre ellas, debemos citar, por un lado, los aportes realizados por Gabriela Iuso, Adil Podhajcer, Rodolfo Puglisi, Luz Roa y Mayra Lucio en los seminarios de Antropología del Cuerpo de la UBA; por Patricia Aschieri en la materia Teoría General de Movimiento de la UBA; y por Yanina Mennelli y Julia Broguet en los seminarios de Antropología del Cuerpo de la UNR. Por otra parte, Pablo David Galván y Ariadna Solís colaboraron en la sistematización y análisis de las encuestas a los estudiantes y las estudiantes, y Wanda Balbé apoyó la selección y edición de los videos que acompañan este escrito.

\section{De la crítica a la modernidad/colonialidad a la performance-investigación intercultural}

Para comenzar nuestra reflexión, compartiremos la intervención que propusimos en la mesa Corporalidad, perfomatividad y prácticas de enseñanza, en el XI Congreso Internacional de Ciencias Sociales y Humanas celebrado en la Universidad de Medellín en 2019. Allí, invitamos a los y las participantes a un breve ejercicio autogenealógico, cuyas consignas transcribimos a continuación:

Cerremos los ojos y tratemos de rememorar cómo usábamos nuestros cuerpos mientras éramos estudiantes en la universidad y tomábamos clases en las aulas... Elijan una de estas situaciones, que haya sido la más habitual, la que ocupaba la mayor parte del tiempo en la universidad, y tratemos de recrear cómo era la experiencia corporal en esa situación.

\footnotetext{
En este trabajo utilizaremos un lenguaje inclusivo que supere la generalidad masculinizada, incorporando el artículo femenino mediante el uso complementario de "los" y "las". En este sentido, nos parece importante señalar que en Argentina hace ya varios años se ha instalado en el uso público, incluso en las esferas estatales, este tipo de lenguaje. Y ha sido incorporado, especialmente, en el ámbito universitario, sobre todo en las carreras de ciencias sociales, humanidades y artes, sumando también el lenguaje referido a las sexualidades no binarias a través del uso de la letra "e". Por este motivo, y como nuestra investigación se centra en este ámbito, hemos decido incorporarlo en nuestros escritos, como forma de adherir a un movimiento que se propone superar el heterosexismo y el falocentrismo desde el lenguaje mismo.
} 
Una vez realizada esta recreación, los y las invitamos a hacerse las siguientes preguntas:

En esta situación, ¿estaban solos, solas o acompañados?, en caso de elegir la segunda opción ¿cómo eran las distancias corporales con los cuerpos de los otros y las otras?

¿Cómo es el espacio en el que se dio esa situación: cerrado-abierto, oscuroiluminado?

¿Qué objetos intervinieron... que materialidades sensibles, afectantes?

¿Cómo caracterizan a los cuerpos presentes, según tamaño, forma, color?

¿Cómo estaban vestidos?

¿Qué tratamientos aplicados al cuerpo percibieron (maquillajes, tatuajes, peinados)?

¿Cuál fue la postura corporal predominante: sentados, parados, acostados?

¿Qué partes del cuerpo pusieron en movimiento y cuáles dejaron quietas?

¿Realizaron desplazamientos por el espacio? ¿Qué formas o diseños espaciales adquirieron?

¿Cómo definirían la temporalidad de los movimientos realizados (lentos, rápidos, moderados)?

¿Cómo fue el flujo de energía o dinámica que involucraron? (continuo, entrecortado)

¿Cuál fue el tono muscular predominante (tenso, relajado)?

¿Qué sentidos perceptivos utilizaron mayoritariamente?

En esta situación, ¿se hallaban degustando bebidas, comidas o cigarros?

¿Escuchando o produciendo músicas u otras expresiones sonoras?

¿Qué olores percibieron?

¿Qué emociones asocian a esta situación?

¿Qué deseos e intenciones?

¿Qué ideas?

¿Podrían asociar esta disposición corporal a sus posiciones identitarias en términos sexo-genéricos, étnico-raciales, de clase o de pertenencia geográfica y cultural? Es decir, ¿algunos de estos aspectos podrían estar vinculados a estas adscripciones? ¿Algunas de estas adscripciones modifican los cuerpos en ese espacio institucional, de una manera perceptible? (Registro de una experiencia de taller, 25 de mayo de 2019)

Luego les pedimos que abrieran los ojos y que realizaran un autorretrato de las memorias sobre cómo usaron su cuerpo la mayor parte del tiempo que pasaron en la universidad. Se les solicitó que intentaran señalar aquellas partes 
en las que fijaron su atención, y que intentaran retratar también sus posiciones identitarias en esa situación (sexo-genéricas, étnico-raciales, de clase o lugar geográfico), es decir, algunos de los rasgos diacríticos que se inscriben en y se vinculan con sus cuerpos, y que consideren percibidos o registrados por los otros. Para este autorretrato, les pedimos que utilizaran fundamentalmente algún lenguaje visual o performático que permitiera una captación sintética de la experiencia vivida a quienes lo percibieran. Podían realizar un dibujo, fotografiarse o realizar un autorretrato performático con una postura o secuencia breve de gestos y movimientos, tal como se muestra en la figura 1.

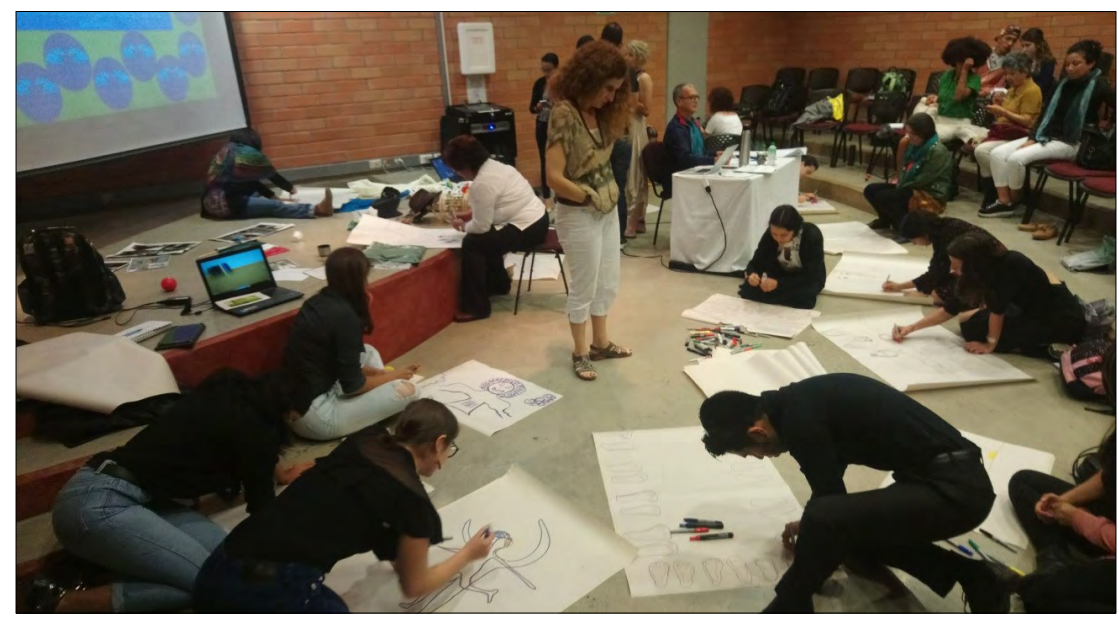

Figura 1. Autorretratos en la mesa de trabajo Corporalidad, performatividad y prácticas de enseñanza, XI Congreso Internacional de Ciencias Sociales y Humanas, Facultad de Ciencias Sociales y Humanas, Universidad de Medellín

Fuente: Hilderman Cardona-Rodas, archivo personal, 2019.

Los autorretratos realizados por los participantes y las participantes encontraron puntos de convergencia con los documentados en otros espacios académicos y también con nuestras propias genealogías. Para nosotras, la educación universitaria y la artística transitaron por vías separadas. Por ello, las experiencias ligadas al movimiento corporal creativo estuvieron circunscritas al ámbito institucional de escuelas públicas y privadas de arte, pero ausentes en nuestras formaciones académicas en ciencias sociales. En este último ámbito, primero como estudiantes y luego como docentes e investigadoras académicas abocadas al estudio del cuerpo, vivimos así nuestra corporalidad: sentadas, leyendo y escribiendo artículos, tesis y libros sobre el cuerpo en movimiento. También, mayormente sentadas, compartíamos nuestras reflexiones sobre el cuerpo en nuestras clases, ponencias y conferencias. Mientras esto sucedía, la mayoría de nuestras "audiencias" (fueran estudiantes u otros colegas) también 
solían estar sentadas y más calladas que nosotras, hasta que cada tanto (especialmente cuando llegaba el momento de las preguntas), sus aquietados y silenciosos cuerpos parecían empezar a revivir con algunos gestos, risas y palabras ${ }^{3}$. Este aquietamiento de nuestros cuerpos en el ámbito académico comenzó a ser vivido por nosotras como una escisión, una especie de doble vida: artistas por un lado, científicas por el otro. Paradójicamente, las múltiples teorías que abundantemente citábamos en nuestros artículos-ponencias-libros, argumentaban sobre los modos en que las percepciones sensibles, gestos y movimientos corporales eran capaces de generar saberes, afectaciones y agenciamientos. Esto quiere decir que en las ciencias sociales y humanas, incluso en ciertos autores ligados a las neurociencias, existe hoy un consenso bastante generalizado acerca de que las diversas problemáticas humanas ya no pueden seguir eludiendo nuestra dimensión encarnada o corporal, sino que es necesario reconocer la potencia intrínseca que esta involucra. Solo a manera de una cartografía (figura 2) exponemos aquí una serie de autores y conceptos que han sido clave para llegar a este consenso, en tanto comparten la crítica a los planteamientos iniciales del dualismo racionalista de Descartes, que redujo el cuerpo humano a una cosa extensa o pura materialidad ${ }^{4}$.
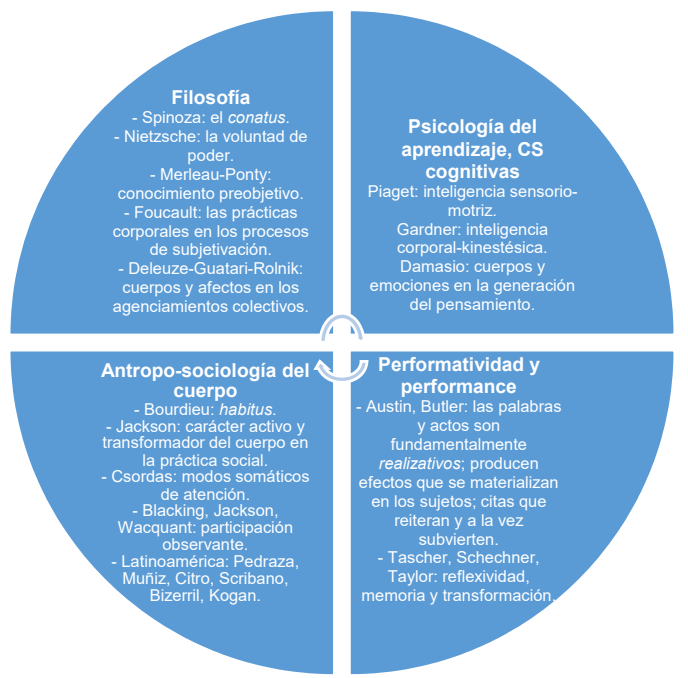

Figura 2. Corporalidades generadoras de saberes, afectaciones y agenciamientos (crítica al dualismo racionalista)

Fuente: elaboración propia.

3 Existen diversos trabajos que analizan críticamente los modos disciplinantes en que han sido concebidos y utilizados los cuerpos en los ámbitos escolares. En el caso de Argentina, puede citarse a Milstein y Mendes (1999); Aisenstein (2006); Morgade y Alonso (2008); Bravin (2013); Varea y Galak (2013), entre otros.

4 En trabajos anteriores, analizamos los vínculos entre los autores y conceptos aquí mencionados (Citro, 1997; $2009 ; 2010)$. 
A pesar de esta nutrida genealogía teórica, la corporalidad sensible (con sus distintas percepciones sensibles y afectaciones), en movimiento y creando vínculos con otros, rara vez es utilizada como una alternativa eficaz para la creación de conocimientos en un aula universitaria en ciencias sociales y humanas, aunque sí lo sea en la vida. Por ello, sostenemos que este problema ontológico y epistemológico en torno al persistente dualismo que aún desconfía y condena las potencias del cuerpo, ha sido principalmente un problema político. En este sentido, se intersecan diversas genealogías de disciplinamiento y violencia sobre las corporalidades, las cuales son, en América Latina, inseparables de los complejos procesos de la colonialidad/modernidad ${ }^{5}$.

Especialmente desde la modernidad tardía europea, se fue construyendo y legitimando una ontología en la que el cuerpo era una "parte" de la persona, la parte material y sobre todo natural o animal —en tanto nace, se alimenta, crece, se reproduce, enferma, cura y muere-, regido por las leyes científicas y cuasi universales de la biología. No obstante, como ya demostró el antropólogo francés Marcel Mauss en 1936, hoy sabemos que todos estos procesos vitales y hasta los mismos modos de usar nuestra corporalidad en la vida cotidiana, son producto de las relaciones sociales, los significados y valores histórico-culturales en los cuales los denominados Homo sapiens nacemos, crecemos, nos reproducimos y morimos. Es importante recordar que a este dualismo ontológico mente/cuerpo también se le superpusieron otros dualismos ontológicos, como el de cultura/ naturaleza y sus derivaciones sexo-genéricas y étnico-raciales: en los dualismos hombre/mujer y civilizados/primitivos. La crítica feminista, así como las teorías poscoloniales, se han encargado de develar la construcción histórico-cultural de estos patrones.

Ahora bien, esta ontología dualista se fue encabalgando con otros tantos dualismos epistémicos concomitantes, como los de razón/emoción, teoría/ práctica, abstracto/concreto. Si bien en el siglo XVII europeo esta diferenciación cartesiana entre la cosa extensa (materia) y el pensamiento, fue una fértil concepción epistemológica para comprender de un modo renovado el funcionamiento del mundo físico y natural para desplegar los conocimientos científicos en esos campos, resultó inadecuada para entender el dinámico y más imprevisible mundo de la vida humana.

En efecto, en el mundo humano, los procesos fisiológicos, las sensaciones, las emociones, los lenguajes y los pensamientos se entrelazan en una misma experiencia vital que no puede ser escindida. Así lo demostraron los filósofos, psicólogos, antropólogos y sociólogos que confrontaron el dualismo racionalista

Los fragmentos que siguen en este apartado retoman algunas argumentaciones desarrolladas con más detalle en ponencias y publicaciones anteriores (Citro y Equipo de Antropología del Cuerpo y la Performance, 2015; Citro, 2018 y 2019). 
de diversos modos y que citamos en la figura 2. Pero también agregaríamos a muchos pueblos colonizados que ni siquiera imaginaron que existía algo denominado cuerpo como separado de la persona o que la razón humana podía operar escindida de los sentimientos o emociones que afectan al ser.

En suma, desde esta perspectiva poscartesiana y holista elaborada desde diversos campos del saber científico y del saber-hacer de distintas culturas y grupos sociales, podemos argumentar que, en tanto somos seres encarnados, toda reflexión humana se origina en las experiencias senso-afecto-cognitivas de nuestras corporalidades en-el-mundo. Como resumía poéticamente Artaud (2005) "nunca hubiera nacido una idea sin el trabajo efectuado un día por el cuerpo..." (p. 20). Por ello, como adelantamos, la persistencia del dualismo y sus desvalorizaciones de los cuerpos sensibles y en movimiento no puede explicarse solamente como consecuencia de la inercia de un antiguo modelo ontológico y epistemológico, sino que implica una dimensión fundamentalmente política: es inseparable de los distintos procesos micro y macro políticos de dominación sobre los cuerpos que se han ido articulando desde la modernidad/colonialidad, intersecando diferenciaciones sexo-genéricas, étnico-raciales y de clase. Resumidamente, diremos que estos procesos abarcan los disciplinamientos biopolíticos en las instituciones de la modernidad occidental (Foucault, 1987), la consolidación de la burguesía como clase social dominante con su peculiar gestión de las corporalidades y emociones (Elías, 1993), la heteronormatividad y el patriarcado como matriz dominante de las relaciones sexo-genéricas (Butler, 1999, entre otras autoras) y los procesos de racialización y discriminación de las poblaciones que sustentaron la explotación de territorios, recursos y personas en el capitalismo extractivista colonial y poscolonial (Fanon, 2009; Quijano, 2000).

En estos procesos, las instituciones escolares de la modernidad operaron como un espacio social clave no solo para reproducir el dualismo cuerpo-mente, sino también para asegurar el disciplinamiento de los cuerpos y la regulación de las emociones. De esta manera, reorganizaron la antigua tradición escolástica y la dotaron de una renovada eficacia: formar cuerpos-personas "más útiles" a los fines institucionales (aquí, la reproducción de un saber racionalizado), pero a la vez más "obedientes [...] en términos políticos" (Foucault, 1987). Así, garantizaron la disminución de la potencia creadora de los cuerpos colectivos, sensibles y en movimiento. Otro aspecto geopolítico para tener en cuenta es que cuando estas pedagogías fueron trasplantadas a América Latina como parte de los procesos de modernidad/colonialidad, generaron diversos epistemicidios, pues no solo se conquistaron territorios y cuerpos, sino también modos de saber-hacer. Como han destacado los estudios decoloniales, la expansión colonial convirtió la racionalidad tecnocientífica moderna en el único modelo válido de producción de conocimiento, dejando por fuera cualquier otro tipo de ontologías y epistemes 
generadas en nuestros territorios, como son las amerindias, afroamericanas y las mestizo populares (Dussel, 2000; Lander, 2005; Mignolo, 2005; Souza Santos, 2010). Y, como ya sabemos, cuando la vigilancia y el disciplinamiento no fueron suficientes, las violencias del castigo corporal y las guerras acecharon a aquellos cuerpos otros que pretendieron seguir resistiendo. He aquí otra de las articulaciones políticas primordiales de estos patrones de la colonialidad/ modernidad, entre disciplinamientos y violencias inscriptas en los cuerpos:

Cuando el cuerpo es considerado la mayor parte del tiempo como una "cosa" (pues es escindido del "verdadero ser" situado en la razón) y cuando se lo ha insensibilizado (obturando su capacidad sensible y afectiva a través del ejercicio continuado de las rutinas disciplinares y la autorregulación emocional), las personas se transforman más fácilmente en un territorio fértil para el ejercicio de diversos disciplinamientos y violencias. Las violencias que el racismo de unos ha ejercido sobre los cuerpos esclavizados y colonizados de otros, pero también las violencias de clase sobre los cuerpos de los y las trabajadores/as, a menudo apelaron, más o menos explícitamente, a esta ideología dualista e insensible ante el dolor del otro: aquellos que se auto-percibían como superiores en razón, justificaban su derecho a explotar los cuerpos de otros cuya razón consideraban inferior o poco desarrollada, en favor de sus ganancias pero también del pretendido "desarrollo de la sociedad", pues bajo su guía racional, esos cuerpos podrían volverse útiles como una rentable fuerza de trabajo o mano de obra. (Citro, 2019)

En conclusión, frente a las pedagogías del disciplinamiento y de la obediencia, oponemos una pedagogía que recupere los cuerpos sensibles y en movimiento, así como las prácticas de libertad. Para enfrentar estas pedagogías de la crueldad (Segato, 2018), hace falta también una pedagogía de la vincularidad basada en la empatía sensible, la dialogicidad y la reciprocidad intersubjetiva e intercultural (Citro, 2019). Una tarea sin duda compleja que, creemos, nos exige empezar a construir nuevos horizontes en torno a una matriz decolonial intercultural, a la manera de una guía que nos permita desmontar esas complejas articulaciones performativas de la colonialidad/modernidad.

Así, con nuestros equipos, hemos comenzado a ensayar las estrategias metodológicas que denominamos "performance-investigación", las cuales fuimos desplegando en los campos de la docencia, la investigación y la divulgación. Estas estrategias:

[...] buscan potenciar la articulación de las dimensiones sensoriales, afectivas y reflexivas de la experiencia, a través de las palabras pero también de la diversidad de gestos, posturas, movimientos, sonoridades e imágenes de los que son capaces nuestros cuerpos; y apelando a este potencial poético-epistemológico-político de las sonoridades y las corporalidades sensibles y en movimiento, intentamos propiciar una reflexividad crítica sobre la diversidad cultural y los regímenes de desigualdad social, y también, ensayar prácticas colectivas de empoderamiento, que propicien la transformación de esas desigualdades y el respeto a la diversidad. (Citro 2018, p. 279) 
Como podrá apreciarse en los ejemplos que siguen, estas prácticas, por su carácter transdisciplinario e intercultural, involucran un pluralismo y una apertura metodológica. Desde una perspectiva intercultural crítica (Walsh, 2008) o, como sostiene Rivera Cusicanqui (2015), desde una episteme $c h^{\prime}{ }^{i x i} i^{6}$, nos sumamos a la propuesta de ir más allá de los límites de las epistemes de la modernidad/posmodernidad occidental para indagar y experimentar en diálogo y articulación con otras prácticas de saber-hacer: mitos, rituales y estéticas/ estésicas provenientes de los pueblos originarios, afrodescendientes, asiáticos, pero también de otras prácticas populares híbridas o mestizas, rurales y urbanas, las cuales han sido históricamente deslegitimadas por los saberes académicos. Asimismo, nos fuimos nutriendo de todo un conjunto de prácticas (en sí mismas inter o transdisciplinarias) gestadas especialmente en el último siglo, como alternativas críticas a los modos hegemónicos desarrollados en los campos pedagógicos, terapéuticos, artísticos y políticos de la modernidad/ colonialidad $^{7}$. No obstante, como hemos venido advirtiendo en diferentes trabajos, este pluralismo no implica una simple yuxtaposición o montaje, al estilo de cierto relativismo posmoderno multicultural (aunque sí reconocemos que es este un peligro siempre latente). En contraste, sostenemos que:

Cada incorporación y cruce entre teorías y prácticas exige primero una cuidadosa contextualización previa y análisis crítico, así como un posterior ejercicio creativo de trasposición, en el que esa práctica es readaptada y combinada con otras, según los fines y el contexto situacional y sociocultural en el que se realiza cada investigación, creación y/o proceso pedagógico. De ahí que no se trate tanto de técnicas prefijadas, sino de estrategias metodológicas que requieren ser especialmente diseñadas y readaptadas. (Citro, 2018, p. 283)

En suma, no se trata solo de aplicar o transponer una técnica, método o dispositivo específico prefijado, sino más bien de trabajar desde una actitud abierta y plural, pues el devenir específico de cada proceso educativo e investigativo nos guía en la elección táctica de estas estrategias metodológicas. Por tanto, se trata de aprender a dejarnos sorprender y transformar por el trabajo con los otros, a permitirnos nomadizar, combinar, rediseñar, readaptar e incluso improvisar en nuestras metodologías de enseñanza e investigación. En este

Con este término, Rivera Cusicanqui (2015) caracteriza una episteme cuyo poder está en una indeterminación situada que se sabe enraizada localmente a la vez que es común a la humanidad, tomando lo contrario entre sí y lo complementario; un estar situados que nos permita dialogar y construir mundos comunes posibles y deseables.

Entre estas destacamos "la 'pedagogía del oprimido' de Freire (1982) y las diversas experiencias de educación popular (...); las experimentaciones performáticas ensayadas en diversos ámbitos artísticos (...), las modalidades artístico-políticas participativas promovidas por el 'teatro del oprimido' de Augusto Boal en Brasil, los diversos movimientos de 'teatros' y 'danzas comunitarias' y, en el caso argentino, por muchos de los colectivos artísticos surgidos con el retorno de la democracia y luego de la crisis del 2001; las diversas modalidades de 'psicodrama' (Moreno 1993; Kesselman y Pavlovsky 1989); y finalmente, las modalidades de activismo político y prácticas autogestivas que se vienen gestando en diversos movimientos sociales" (Citro, 2018, pp. 281-282). 
sentido, buscamos promover una mayor interrelación entre las prácticas de enseñanza-aprendizaje y de investigación, invitando a que los estudiantes y las estudiantes se conviertan en investigadores e investigadoras de aquellos temas que nos proponemos aprender y enseñar mutuamente. Asimismo, nos parece importante que los investigadores sociales y las investigadoras sociales se conviertan en aprendices de los diversos grupos sociales que pretenden indagar. De esta manera, se tienden lazos más estrechos entre los componentes de aquella matriz ternaria de docencia, investigación y extensión, en la que se han dividido las universidades en las que nos desempeñamos.

Ahora bien, este pluralismo y movilidad metodológica no propone un relativismo a ultranza, sino que encuentra su límite ético-político en una serie de principios epistemológicos y políticos que, para nosotras, hoy constituyen el horizonte decolonial e intercultural. En la tabla 1 se intenta retratar este horizonte utópico y deseante que inevitablemente se monta sobre estas genealogías críticas de la modernidad/colonialidad ${ }^{8}$.

Tabla 1. Síntesis comparativa entre patrones moderno/coloniales y matrices decoloniales

\begin{tabular}{|c|c|}
\hline Patrones de la modernidad/colonialidad & Matrices del horizonte decolonial-intercultural \\
\hline $\begin{array}{l}\text { Colonialidad de las epistemes y peda- } \\
\text { gogías del "mundo occidentalizado". }\end{array}$ & $\begin{array}{l}\text { Interculturalidad crítica en diálogo con modos } \\
\text { de saber-hacer de diversas regiones y orígenes } \\
\text { culturales (indígenas, afroamericanos, asiáti- } \\
\text { cos, mestizos). }\end{array}$ \\
\hline
\end{tabular}

Especialización de los modos de saberhacer y jerarquización de las relaciones de saber-poder.

Énfasis en el aprendizaje individual en un colectivo normalizado.

Transmisión de contenidos ("educación bancaria").
Interdisciplinariedad y apertura al intercambio con saberes no académicos o subalternizados (culturas populares, urbanas y campesinas).

Énfasis en el aprendizaje intersubjetivo en un colectivo diverso, con momentos de repliegue individual.

Herramientas para reflexionar, pero también para transformar diversas problemáticas sociales (ensayos performáticos de transformación micropolítica).

Cabe aclarar que esta tabla se ha ido reescribiendo, con algunas transformaciones, en los últimos trabajos emprendidos por el equipo (Citro y Equipo de Antropología del Cuerpo y la Performance, 2015; Citro, 2018). 
Logocentrismo de la razón-palabra. Lenguajes analíticos y conceptuales:

- Neutralidad afectiva.

- Uso preferencial de la vista y el oído.

- Perspectiva que resalta la importancia de la observación, la escucha y la distancia como fuentes de una ansiada objetividad.
Performances: palabras-sonoridades, gestosmovimientos, imágenes (audio)visuales, olfativas, táctiles y gustativas; lenguajes estéticos, míticos y rituales; y lenguaje analíticos y conceptuales.

- Diversidad de afectaciones.

- Diversidad de modos perceptivos.

- Multiplicidad de los puntos perceptivos, en movimientos situados entre la distancia analítica y el acercamiento participativo.

Micropolíticas de las prácticas de libertad y vincularidad:

-Propiciar la horizontalidad y reciprocidad entre las diversas posiciones institucionales.

- La circulación por distintas "posiciones identitarias" para generar empatía y reciprocidad de los puntos de vista.
- Organización de los procesos (especialmente pedagógicos y productivos) en esquemas evolutivos prefijados de complejidad creciente, con control de los tiempos y fijación de pruebas.

- Recorridos prefijados en espacios cerrados, con división funcional-jerárquica en zonas y disposiciones rectilíneas que facilitan el ejercicio del poder.

\begin{abstract}
- Procesos que involucran la imitación práctica, los modos analógicos y el juego simbólico como proceso lúdico-creativo que instaura su propia temporalidad colectiva.

- Exploración de espacios abiertos (conexiones con el entorno), generación de espacios institucionales multifuncionales, disposiciones circulares que promueven la vincularidad.
\end{abstract}

Fuente: elaboración propia.

\section{Sistematizando nuestras prácticas educativas en la Universidad}

En los últimos años, nuestros equipos comenzaron a ensayar diversas metodologías de performance-investigación con los estudiantes universitarios y las estudiantes universitarias; también en los espacios académicos de congresos y conferencias. Al principio, estos ensayos se dieron de manera más o menos experimental e intuitiva y posteriormente, al comenzar a sistematizar estas experiencias, pudimos advertir tres grandes modalidades con diferentes variaciones: 1) aquellas que apelan al impacto senso-perceptivo y afectivo de lo que denominaremos materialidades afectantes, no habituales para el espacio del aula; 2) las que, en cambio, invitan al ejercicio de una memoria encarnada y una reflexión analítica sobre las propias experiencias vividas y genealogías; 3) las que incitan a elaborar ensayos performáticos colectivos del imaginar-desear que ponen en escena posibles transformaciones de nuestras prácticas socioculturales. Como veremos, 
estas modalidades abrevan en diferentes antecedentes y suelen producir diversos efectos o resonancias en los estudiantes y las estudiantes. Asimismo, tienden a focalizar en las distintas dimensiones temporales de la experiencia: la inmanencia del cuerpo presente, la memoria sobre el pasado y la proyección creativa de otros futuros posibles. Tal vez por todo ello, cada vez más tendemos a combinarlas en una misma clase, por lo cual describiremos también algunos ejemplos de estas modalidades híbridas.

Es importante aclarar que no pretendemos construir didácticas prefijadas con esta sistematización, pues cada contexto y situación específica demanda sus propias articulaciones y producirá diferentes resonancias. Por ello, consideramos necesario efectuar una breve caracterización de los contextos en que estas prácticas educativas han sido ensayadas. Estas se iniciaron en carreras de ciencias sociales y artes, en la Facultad de Filosofía y Letras y la Facultad de Ciencias Sociales de la Universidad de Buenos Aires y en la Facultad de Humanidades y Artes de la Universidad Nacional de Rosario, dos universidades estatales de Argentina que reciben principalmente estudiantes jóvenes (aunque hay también algunos adultos y adultos mayores).

La mayoría de argentinos tienen ascendencia blanco-europea y de clase media, aunque cabe aclarar que la UBA suele recibir cada vez más estudiantes de intercambio de países latinoamericanos y, en menor medida, europeos. Además, ambas universidades son de acceso libre (pues no hay restricciones en el ingreso) y gratuito en sus pregrados. Además, las facultades mencionadas tienen una intensa historia y un presente de movilización política estudiantil, lo cual crea espacios institucionales bastante peculiares, cargados de estéticas, simbolismos y actos políticos. Con el tiempo, también fuimos llevando este tipo de experiencias a universidades de otros países como Colombia, Chile, Ecuador, España, México, Perú, Uruguay, Chile y más recientemente a Noruega, en una maestría internacional que recibe estudiantes de todo el mundo. En la mayoría de los casos se trataba de estudiantes con ese similar perfil económico-social, y en Latinoamérica, con una mayor diversidad étnico-racial que a la que estábamos acostumbradas en Argentina, lo cual emergía en la diversidad de saberes encarnados que movilizaban las prácticas propuestas. A pesar de estas diferencias, los estudiantes y las estudiantes han acogido de manera muy entusiasta estas metodologías.

\section{Desde las materialidades afectantes}

Las estrategias que apelan al impacto senso-perceptivo y afectivo, intentan producir cierto extrañamiento o asombro frente al contenido tratado, movilizando materialidades afectantes en principio impensadas o no habituales para el aula. 
Utilizamos aquí el término materialidades afectantes para designar una amplia gama de materiales de distinta procedencia (natural, tecnológica, artificial), cuyo comportamiento plástico y algunas veces efímero y cambiante, se va transformando en los vínculos con los participantes y las participantes. Así, estas materialidades involucran, además de nuestras corporalidades, objetos, sonoridades, olores, gustos y espacialidades, es decir, toda manifestación actual en el mundo que pueda ser percibida con nuestros sentidos (y no solo imaginada o pensada introspectivamente), y que tenga la peculiaridad de suscitar una particular atención o puesta en foco perceptivo, la cual en muchos casos deviene de la labor estético-reflexiva que los ha investido.

Esta noción de materialidad afectante abreva en algunas propuestas del giro ontológico y de los estudios de performatividad, en los cuales hay una fuerte crítica a la reificación de los entes y los seres. En términos de Ingold (2012), se trata de ir desde la objetividad de las cosas hacia los flujos de los materiales con la intención de desontologizar y poner el acento en el hacer y en la interacción de la materia, que siempre posee una historia de afectaciones. Trabajar desde las materialidades afectantes no implica tanto apelar al objeto en sí mismo, sino más bien al fenómeno que suscita en su interacción con la percepción, la sensibilidad, los imaginarios y las reflexividades de los sujetos en sus vínculos con otros y con el entorno.

De la misma manera, la noción cosas mediadoras de Latour (2005) insiste en la capacidad de los entes para cocrear una historia, no solo para transportar un símbolo o una idea externa a ellos, sino para crearla en el mismo proceso de la comunicación y el hacer. Así, constatamos que el trabajo sobre las materialidades en el aula, al promover la puesta en foco de estos movimientos de descontextualización y recontextualización de entidades y cosas (es decir, provocando un cambio en el devenir de sus propias historias), tiene el potencial de movilizar los flujos en los cuales estos se encuentran solidificados o anquilosados, desde el imperativo de habitus, normas o de situaciones de violencia. Por tanto, la intención de esta modalidad de trabajo es que, mediante estos movimientos, se desnaturalicen estas historias sedimentadas y se abra una brecha para la crítica y el ensayo de nuevas historias posibles.

Dentro de estas estrategias que apelan al impacto y la afectación directa, pudimos identificar dos variaciones. En la primera, es el docente quien propone inicialmente alguna materialidad afectante provocadora a los estudiantes y las estudiantes; en la segunda, el docente-investigador promueve que los estudiantes y las estudiantes indaguen y traigan al espacio de la universidad alguna de estas materialidades. 
Uno de los primeros ensayos que hicimos de la primera modalidad surgió para la clase en la que trabajaríamos la noción cuerpos dóciles de Foucault en nuestro seminario Antropología del Cuerpo de 2013 en la UBA, y fue diseñada por Silvia junto con Mayra Lucio. En ese momento, Silvia desempeñó el rol de "la profesora disciplinar" y Mayra de la "celadora-panóptica". Esta clase fue luego repetida en 2018. A continuación, algunos fragmentos del registro de estas clases:

Desde el inicio, los/las estudiantes eran convocados a integrarse a una performance intensamente disciplinar, en la que experimentaban en carne propia cada una de las facetas de la disciplina. La profesora contabilizaba y marcaba espacialmente a los/las estudiantes al comienzo de la clase, en función de su promedio. Se les hacía formar fila antes de entrar al aula y se les indicaba que se ubicaran en el espacio en función de esa clasificación. Al ingresar, se les leía el reglamento, que estipulaba el comportamiento a seguir: la postura corporal correcta y eficaz (el modo de sentarse, incluso la forma de escribir y el apoyo de los pies), los elementos posibles de ser utilizados durante la clase (lápiz y papel), y los tiempos prefijados para escuchar, escribir y responder a las preguntas de la docente. Se prohibía todo objeto y todo movimiento que pudiera interrumpir la atención. La profesora a cargo desarrollaba los contenidos de Vigilar y castigar en un Power Point, de forma estructurada, con tiempos prefijados para cada pantalla-mapa conceptual, y evaluaciones parciales, de complejidad creciente. Mientras tanto, la celadora observaba y registraba a los/ las estudiantes con una cámara filmadora durante todo el transcurso de la clase, y advertía a la docente, cuando algún estudiante no respetaba la postura corporal o los tiempos prefijados, para ser así corregido, y eventualmente, sancionado [sic]. (Registro de una experiencia de taller, 8 de junio de 2013)

Los comentarios de los estudiantes y las estudiantes sobre esta clase acentuaron la incomodidad vivida, en especial por la impostura de estar derechos y por la prohibición de tomar notas mientras la docente hablaba. Asimismo, disparó muchos recuerdos de su paso por el colegio secundario, como lo expresaba una estudiante:

En lo afectivo algunas cosas me hicieron acordar a mi escuela secundaria, cuando durante el dispositivo hablaban de los tiempos, de la eficacia, de la cantidad de horas que teníamos que estar, etc. me hizo acordar al director de mi escuela hablándonos sobre todas las horas que pasábamos en la escuela y que eso nos hacía "distintos" al "resto de las escuelas" (iba a una escuela técnica entonces teníamos más horas). (Registro de una experiencia de taller, 8 de mayo de 2018)

Otra estudiante dijo haber experimentado "sentimientos de susto y repugnancia", y "el impulso de levantarme y salir de la clase y al mismo tiempo no me atrevía a moverme". Otro estudiante aludió al acatamiento de las órdenes, diciendo que "los momentos en que reprendían a un compañero fueron incómodos, aunque algo hilarantes. Sin embargo, reprimí cualquier demostración al respecto", y otra afirmaba: 
[...] algo me hacía acordar a la escuela secundaria de todo eso, algo de la norma, del cumplir, del docente como otro separado que observa y dictamina qué está bien y qué está mal y yo ahí haciendo caso a la norma (y la bronca contenida, el querer salir corriendo pero quedarme inmóvil). (Registro de una experiencia de taller, 8 de mayo de 2018)

La experiencia de pasar por una situación disciplinante extrema despertó enojos, miedos y rechazos en los estudiantes y las estudiantes, pero no hubo situaciones de crítica o de indisciplina. Esto nos permitió reflexionar sobre el poder que manejan los docentes y las docentes dentro del aula, incluso cuando este se plantea como un juego, y cómo la norma instituida se reproduce performativamente, con efectos profundos y duraderos, aún en estos espacios. Finalmente, el trabajo les hizo pensar en la eficacia de aprender teoría mientras se la experimenta corporalmente.

Otro ensayo de esta modalidad surgió en la clase en la que trabajamos sobre la noción de performatividad de Judith Butler, en la cual Mayra sugirió invitar a una performer del campo del activismo feminista:

La clase comenzó mostrando una serie de videos asociados a distintas expresiones del erotismo, el cuerpo y el género: el videoclip del tema musical "Papichulo" (un tema de reggaetón hipersexualizado en clave hegemónica, es decir, heteronormativa) y el video de una performance de "posporno". Paralelamente, una performer proveniente del activismo feminista tomaba escena en el medio del aula y comenzaba a sacarse toda la ropa y a ponérsela nuevamente, durante unos diez minutos aproximadamente (el tiempo que duraron los videos). Al final, la performer se sacaba un tampón con sangre de su vagina, que dejaba tirado en el piso del aula, con un redondel a su alrededor marcado con fibrón que tenía una flecha indicando la palabra "mujer", escrita también en el suelo. Las estudiantes estaban bastantes sorprendidas, pero a la vez inmovilizadas, solo una de ellas atinó a preguntar: ¿nos vamos a quedar así mirando?; a lo cual docentes y performers respondieron que podían hacer lo que desearan.

Posteriormente, al final de la clase, se propuso bailar una "cumbia" de tres maneras distintas: la primera, "normalmente", es decir, como cada unx sabía hacerlo sin pensar; la segunda, como si nos autopercibiéramos como "mujeres" apelando a estereotipos de lo que cada unx comprendiera como "mujer"; y la tercera, lo mismo, pero caracterizando a un "varón". Para concluir, se hacían cruces de caracterizaciones y una puesta en común de lo que había sucedido en estos tres "bailes", qué patrones emergentes se habían podido reconocer en cada momento, y también, se lo relacionó con la performance anterior [sic]. (Registro de una experiencia de taller, 8 de abril de 2013)

Como puede apreciarse, esta clase combinó el impacto de la percepción de una performance no habitual para el aula (el cuerpo de una performer vistiéndose y desvistiéndose, mostrando su sangre menstrual es aún recordado y comentado entre los estudiantes), con la exploración encarnada de las propias 
memorias corporales de los estudiantes y las estudiantes (el baile habitual de cumbia) y un ensayo performático creativo (bailar como el género opuesto). Así, esta experiencia permitió reflexionar sobre la performatividad y sus diversos efectos en las corporalidades-subjetividades y, sobre todo, permitió que los estudiantes y las estudiantes pudieran advertir y experimentar cómo operan los patrones hegemónicos, pero también cómo pueden ser subvertidos en sus propias corporalidades ${ }^{9}$.

Otra estrategia de este tipo emergió en una clase sobre prácticas afroamericanas y discriminación étnico-racial y religiosa, en 2017 y 2019, en el seminario Artes, culturas y sociedades en América Latina de la Maestría en Estudios Sociales Latinoamericanos de la Facultad de Sociales de la UBA. En esta clase, Manuela propuso elaborar una instalación performática ambientada en una ceremonia de Quimbanda (una de las variantes de las religiones afrobrasileñas, difundida en Argentina), la cual incluía bebidas, comidas y aromas. Luego se realizó una modalidad de taller en el cual se cantaron y bailaron danzas provenientes del universo religioso del candomblé bahiano y se finalizó con la exposición de cuestiones teóricas y etnográficas de diversos autores (figuras 3 y 4).

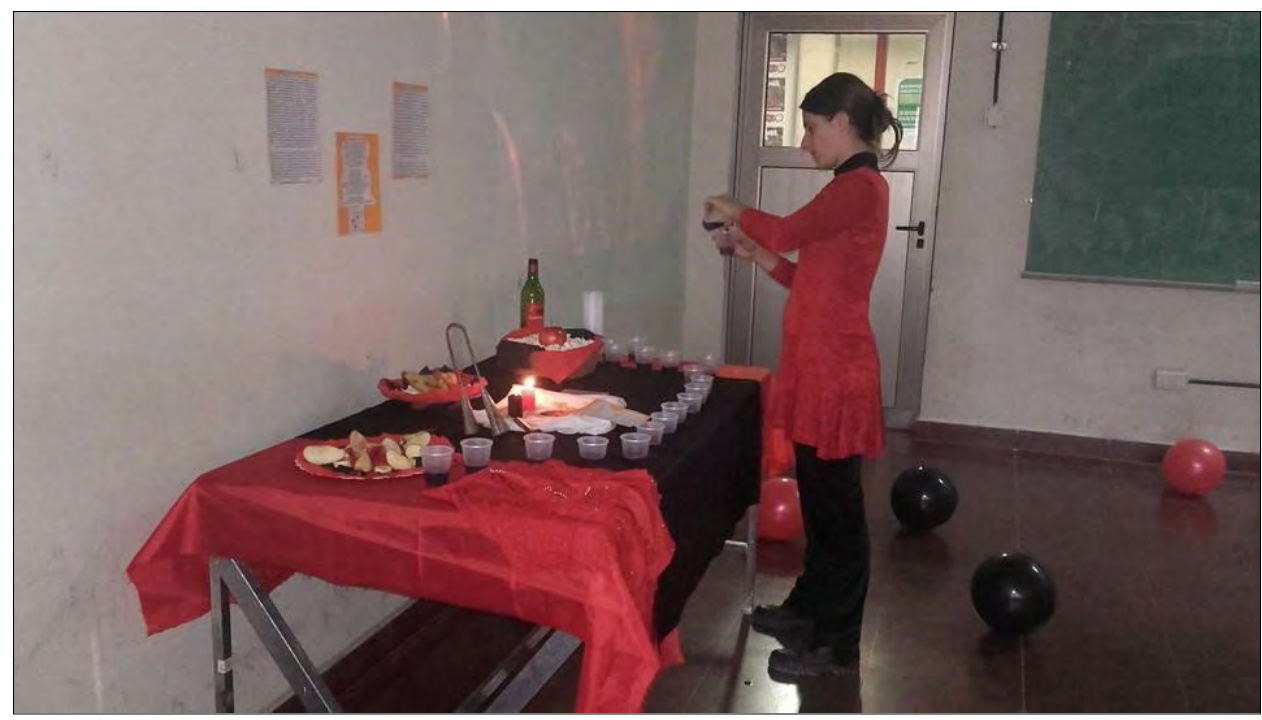

Figura 3. Instalación performática. Facultad de Ciencias Sociales, UBA, 2017

Fuente: Citro, archivo personal, 2017.

Algunas imágenes en video de estas y otras clases pueden verse en el siguiente enlace: https://www. antropologiadelcuerpo.com/index.php/cursos-overview/cursos-overview-2/812-seminario-de-introducciona-la-antropologia-del-cuerpo-2013-uba. 


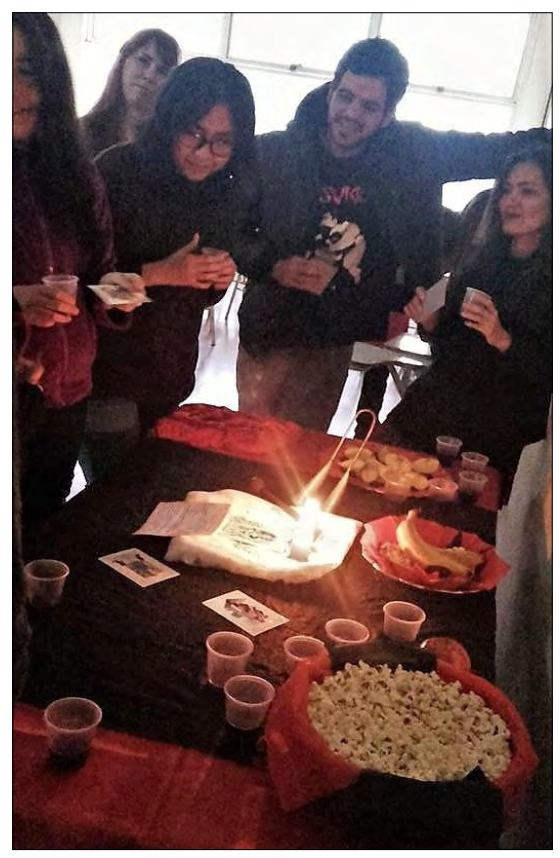

Figura 4. Instalación performática. Facultad de Ciencias Sociales, UBA, 2017

Fuente: Citro, archivo personal, 2017.

El objetivo fue trabajar con las sensaciones e imaginarios que despertaba ese "mundo afro" a partir de las diversas materialidades convocadas, para luego llevar la atención hacia sus significaciones culturales, así como a su proceso de invisibilización y exotización, producto de los legados coloniales racistas en nuestros países. En ambas clases pudimos advertir que los estudiantes que provenían de Colombia, Venezuela, Cuba o Brasil solían traer instantáneamente recuerdos y situaciones vividas vinculadas a las prácticas religiosas afro de sus contextos cotidianos. En cambio, los estudiantes argentinos y las estudiantes argentinas manifestaban una perspectiva más laica, secular y racionalista que los llevaba a desconfiar sobre este mundo. Algunos fragmentos de nuestros registros:

En la clase de 2019, un joven de Venezuela comentó que uno podía encontrar religiosos vestidos de blanco por las calles (aludiendo a la vestimenta característica que usan los devotos en sus períodos de iniciación), e incluso a algunos profesores en la Universidad. En cambio, los/las estudiantes argentinxs lo primero que manifestaron fue su desconfianza hacia la "magia negra". El vínculo con la Umbanda hacía surgir apreciaciones sobre la religiosidad popular vinculada a lo "mágico", e incluso cierta sospecha sobre el papel de los jefes religiosos y su carisma para "engañar" o "manipular" a los fieles [sic]. (Registro de una experiencia de taller, 21 de junio de 2019) 
Estas diferentes apreciaciones dieron el puntapié para reflexionar sobre los distintos procesos de racialización y de construcción de nación en América Latina, aunque la deslegitimación e impugnación que atraviesa muchas de las prácticas vinculadas a tradiciones afroamericanas, en especial en los procesos de blanqueamiento que sufrieron nuestros países. Mediante la comparación fue posible problematizar las herencias moderno/coloniales de diferenciación social aún presentes en nuestros contextos.

Como puede apreciarse en estos diferentes casos, las materialidades que solemos utilizar se caracterizan por convocar los diferentes sentidos perceptivos, más allá de los visuales. Cabe aclarar que también reconocemos la eficacia de trabajar con fotografías, pinturas, videos o películas como objetos condensadores de temáticas y problemáticas socioculturales, capaces de provocar fructíferos debates. De hecho, los utilizamos en nuestras clases. No obstante, dado el énfasis de lo visual en nuestra sociedad contemporánea y la anestesia de los otros modos somáticos de atención que promueve, nos ha interesado desplegar también aquellos sentidos menos explorados en las aulas más tradicionales de nuestras universidades, como son el cinestésico, la tactilidad, el gusto y el olfato.

En una segunda variación de estas estrategias, el docente-investigador y la docente investigadora promueven que los estudiantes y las estudiantesparticipantes perciban, busquen y traigan al espacio de la universidad alguna materialidad afectante que condense, represente, simbolice o resuene con alguno de los contenidos a tratarse, para disponerlo en una instalación o performance colectiva. Estas materialidades pueden ser objetos cotidianos o estéticos, una comida-bebida o aroma, una imagen (foto, dibujo, video breve), sonidos, cantos o músicas, un texto poético o cuento, un gesto, movimiento o breve montaje de acciones performáticas que quieran realizar. Esta estrategia la hemos desarrollado en nuestras clases sobre la noción de cuerpo sin órganos en Deleuze y Guattari (1994), en una clase comparativa sobre la voluntad de poder en Nietzsche (2001) y ser-en-el mundo en Merleau-Ponty (1993), con estudiantes de Artes y Antropología de la Facultad de Filosofía y Letras de la UBA. Estas prácticas surgieron a partir de trabajos de performance-investigación con instalaciones artísticas y con objetos/elementos cotidianos de las propias biografías, que venían haciendo con otra integrante del equipo de la UBA, Adil Podhajcer.

En el caso de las materialidades afectantes movilizadas por Nietzsche, luego de que cada estudiante y subgrupo presentara sus materialidades y comentara los vínculos que había encontrado, se produjo una articulación o montaje de movimientos, sonidos, palabras y objetos que devino en una caravana-performance que salió a recorrer los pasillos de la facultad: un agenciamiento colectivo de 
materialidades intensivas que encarnó aquella noción de voluntad de poder ${ }^{10}$. Así lo expresaron luego los/las estudiantes:

En el momento en el que estaba debajo de la capa roja de Nietzsche sentí una suerte de sentimiento colectivo y de compañerismo entre pares (incluyendo a la profesora que se encontraba al lado de nosotros como una más). También, al ser "anónima" debajo de la capa, sentí liberación al momento de decir y gritar lo que quisiera (liberándome de los estereotipos y roles que me pertenecen por ser estudiante de la facultad). (Registro de una experiencia de taller, 12 de abril de 2017)

\section{Otro comentario enfatizaba:}

es interesante que al construirse este cuerpo colectivo mancomunado en el que desaparecía el cuerpo singular como factor de individuación, pude tener una experiencia más cercana (...) a la desmesura, a la pérdida de los límites de mi cuerpo con el mundo y con los otros. (Registro de una experiencia de taller, 12 de abril de 2017)

Como puede apreciarse, el pasaje de lo individual a lo colectivo conecta las materialidades afectantes, permite comprender carnalmente las nociones de intersubjetividad y de poder propuestas por estos autores.

Finalmente, un último ejemplo fue nuestra sugerencia para la corpoinstalación colectiva con la que iniciamos la mesa de trabajo en el mencionado congreso de la Universidad de Medellín (figura 5). Para ello, se le pidió a cada ponente que trajera consigo una materialidad que evocara alguna dimensión de su trabajo.
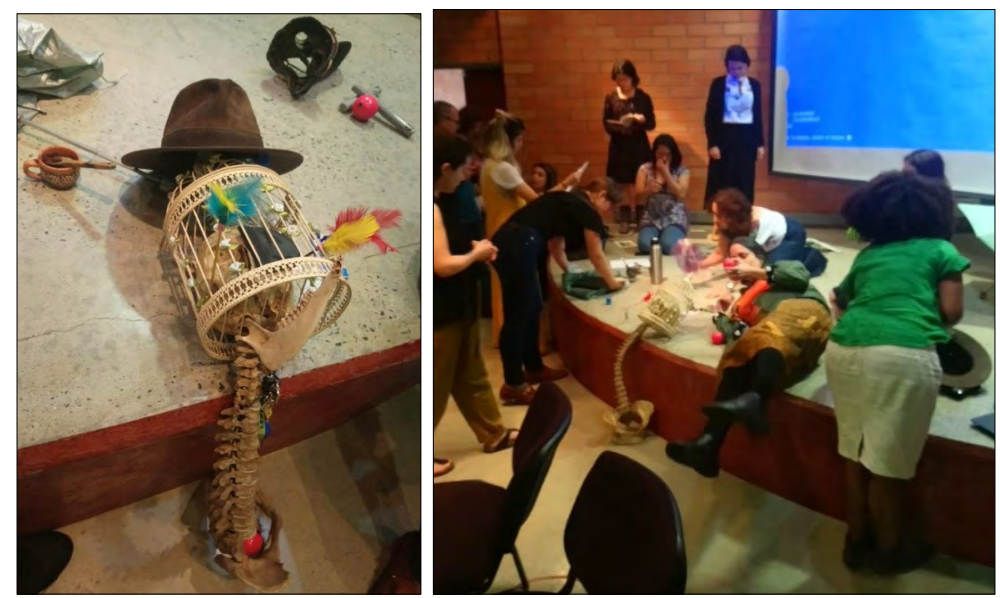

Figura 5. Corpoinstalación, en la apertura de la mesa de trabajo Corporalidad, perfomatividad y prácticas de enseñanza, XI Congreso Internacional de Ciencias Sociales y Humanas, Facultad de Ciencias Sociales y Humanas, Universidad de Medellín

Fuente: Hilderman Cardona-Rodas, archivo personal, 2019.

10 Algunas escenas de esta clase pueden verse en el siguiente video: https://vimeo.com/354279766 
Reflexionando sobre los posibles antecedentes de este trabajo con las materialidades, encontramos que este abreva sobre todo en el campo de las artes: las primeras modalidades, especialmente en las artes de la performance, el activismo y el artivismo, campos de los que justamente provienen nuestra colega Mayra y nosotras mismas; las segundas, en las instalaciones y performances de las artes visuales, del que proviene Adil. En ambas modalidades, se trata de prácticas estético-políticas que intervienen en los espacios públicos o institucionales habituales. Con ello, se busca impactar desde lo sensible para desnaturalizar lo instituido y movilizar nuevas preguntas, reflexiones y afectaciones a través de signos que operan indexicalmente.

Tal vez por ello encontramos que hemos apelado a este tipo de prácticas en los casos en que trabajábamos temas y autores que promovían una deconstrucción reflexiva de los procesos de violencia, disciplinamiento y normalización de los cuerpos, tanto en las micropolíticas de las instituciones de la modernidad (los ejemplos de Nietzsche, Foucault, Deleuze y Guattari), como de segregaciones y jerarquizaciones sociales basadas en la clasificación sexo-genérica (el ejemplo de Butler) y étnico-racial (el de los legados afroamericanos y el de Fanon, que luego veremos).

Es importante destacar que estas modalidades se vinculan a una concepción contemporánea de las didácticas como "despliegues de signos y pistas", que han venido señalando diferentes autores, y que Gallo (2017) resume así:

Enseñar y aprender consiste básicamente en ofrecer e interpretar los signos que emiten las cosas (Bárcena, 2014, D'Hoest y Bárcena, 2011, Pardo, 2011). (...) Si enseñar tuviese que ver con disponer signos y ofrecer pistas, la didáctica perdería su condición normativa de guía, modelo, método, conducción y ocuparía el lugar del acontecimiento, de la singularidad y de la diferencia (Vitorino, 2015, Corazza, 2015). (...) El acontecimiento es lo que llega, lo que viene por sorpresa y no se puede anticipar, ni programar, ni planificar; depende más del encuentro y de intercambios en la relación educativa. (Contreras, 2010, p. 200)

En lo específico, diríamos que nuestras estrategias movilizan signos de materialidades afectantes, y se acercan así a lo que Gallo (2017) describe como "bloque de sensaciones", es decir, clases diseñadas "desde el compuesto conceptos, afectos y perceptos" que hilvanan "la posibilidad de pensar la educación como acontecimiento y al cuerpo como lugar de la experiencia" (p. 202).

\section{Desde la memoria encarnada y la reflexividad analítica sobre las propias experiencias vividas y genealogías}

Las estrategias que apelan a inducir la memoria senso-perceptiva, afectiva y reflexiva sobre las propias experiencias vividas y genealogías, geopolíticamente situadas, buscan poner en foco y traer a la consciencia prácticas socioculturales 
cotidianas que, por efectos de la rutina, permanecen invisibilizadas. A diferencia de las estrategias anteriores, encontramos que estas no se inician apelando tanto al impacto de una materialidad afectante provocadora, sino más bien al acto de rememorar e indagar aquello que ya conocemos: nuestras experiencias vividas o mundos cotidianos para generar luego un proceso de distanciamiento. Como veremos, estas propuestas se inspiran en diversas modalidades de exploración etnográfica.

Un ejemplo es justamente el ejercicio que propusimos al inicio de este escrito, al rememorar nuestras experiencias corporales en las aulas de la universidad. En el contexto de la docencia universitaria, uno de los primeros ejercicios de esta modalidad surgió para la clase en la que trabajaríamos la noción de habitus de Bourdieu, en nuestro seminario que tuvo lugar en el 2013 de Antropología del Cuerpo en la UBA, y fue propuesto por otra integrante del Equipo de la Universidad de Buenos Aires, Gabriela Iuso:

Esa práctica se iniciaba con aquello que en algunas dinámicas de grupos suele denominarse "caldeamiento", o preparación para la actividad, y que en este caso apuntaba a llevar la sensibilidad y la conciencia al espacio que habitamos, a las otras personas presentes y al propio cuerpo, para de este modo comenzar a generar vínculos entre los/las participantes. Luego, Gabriela les proponía recordar a los estudiantes cómo usaban su cuerpo en la Universidad, e ir retrocediendo en el tiempo, pasando por las diferentes instancias del sistema educativo, hasta llegar al jardín de infantes. Finalmente, a la manera de un juego que se va improvisando en el mismo momento, se invitaba a los participantes a pasar más rápidamente por estas diferentes corporalidades, o también a contrastarlas con momentos más libres, como el recreo, o otras prácticas de la vida cotidiana. Asimismo, se proponía explorar estos movimientos en modalidades expresivas individuales, intersubjetivas y colectivas, en grupos de diversos tamaños. (Registro de una experiencia de taller, 5 de abril de 2013)

Lo peculiar del ejercicio es que no se trataba de explorar estas memorias solo desde las imágenes mentales que proporcionan nuestros recuerdos introspectivos ni tampoco exclusivamente desde el diálogo y el grupo de discusión, sino que también se buscaba encarnar esas memorias con nuestras corporalidades en movimiento. Sobre este trabajo, nos decían dos de nuestras estudiantes:

[...] en la actividad que consistía en expresar corporalmente lo vivido en el jardín, me recordé jugando a saltar y captar con mis manos las partículas del polvo atmosférico que se reflejaban en la luz de la mañana que se filtraba en las ventanas de la escuela. (...) Considero que el cuerpo habilitó a que se pudiera poner en primera persona lo vivido y dejarlo llevar.

Haber realizado una performance sobre las técnicas corporales implementadas en nuestros cuerpos a lo largo de la vida, me permitió notar que las compañeras de mi equipo habían sido atravesadas por técnicas corporales muy similares a las que 
viví yo, lo cual afirmó la idea de que las técnicas corporales no son azarosas, sino que están impulsadas por mecanismos de poder con fines bastante planificados. (Registro de una experiencia de taller, 27 de marzo de 2018)

Una propuesta similar fue realizada por Gabriela para trabajar la noción de performatividad de género de Butler. Para explorar este concepto, ella propuso recordar alguna situación de "incomodidad" que hayamos vivido en relación con nuestra identificación sexo-genérica, es decir, alguna práctica incómoda o displacentera que nos hayamos visto forzados y forzadas a realizar reiteradamente por ser socialmente identificados como "mujeres" $u$ "hombres".

En el caso de Gabriela, su formación como antropóloga, docente de Expresión Corporal y practicante de capoeira y danza comunitaria, la llevaron a explorar metodologías que apelaban a la expresión de los cuerpos en movimiento y al juego colectivo para reflexionar críticamente sobre nuestras corporalidades. Como pudo apreciarse en nuestro ejercicio inicial, la manera de expresar estas memorias puede recurrir tanto al movimiento corporal como a los diversos lenguajes visuales, sonoros u objetos que operan como "cosas mediadoras", en los términos de Latour (2005), con los otros y con el entorno. En este sentido, notamos que la apelación a otras materialidades afectantes más allá del propio movimiento corporal, facilitan la comunicación y la interafectación, especialmente cuando se trata de grupos que no se conocen entre sí, no están habituados al trabajo desde los cuerpos en movimiento o cuando se trabaja en contextos en los que se dispone de poco tiempo y no se puede, por ejemplo, realizar un caldeamiento facilitador.

Una variación y complemento de estas estrategias provino de su articulación con guías de descripción analítica de la experiencia corporal. Así, luego del momento inicial de la memoria genealógica, comenzamos a proponer una descripción analítica más detallada de la experiencia vivida que estaba siendo recordada, focalizando especialmente en el uso de los cuerpos, tal como sucedió en el ejercicio inicial sobre las memorias de las corporalidades en el aula. Estas variables son parte de una guía elaborada para la confección de registros etnográficos, y fue propuesta inicialmente por Citro (2003) en su tesis doctoral. En esta, retomó los abordajes del análisis del movimiento en Laban (1958), la fenomenología de Merleau-Ponty (1993) y del interaccionismo simbólico (Goofman, 1970). Luego, en 2010, fueron reelaboradas en el marco del primer seminario de Antropología del Cuerpo que dimos conjuntamente en la UBA con nuestros equipos. La intención de esta guía era llevar la atención a los aspectos sensoriales y afectivos de la experiencia que a veces tienden a ser descuidados en las investigaciones socio-antropológicas, por el énfasis dado a los discursos obtenidos en entrevistas y conversaciones como material privilegiado del análisis. En suma, esta guía de descripción analítica abreva en la propuesta 
de "la descripción densa" de la etnografía que postula Geertz (1987) y en metodologías de autoetnografía, pero en este caso se aplican especialmente al uso de los cuerpos. Para esto último, también fueron fundamentales los aportes de otra integrante del equipo, Patricia Aschieri, quien en su tesis doctoral (2013) había trabajado desde metodologías de autoetnografía y participación observante en el campo de la danza.

De este modo, buscamos complementar la experimentación desde los cuerpos y las materialidades afectantes con una atención más pormenorizada hacia aquellos aspectos naturalizados que queríamos develar. Así, intentamos también responder a la demanda de nuestros estudiantes que, como sintetizó uno de ellos, insistían en "lo difícil que es poner en palabras las sensaciones de nuestra propia experiencia. Sería interesante encontrar un ejercicio que ayude a esta alfabetización de sensaciones, ya que como estudiantes estamos en pleno proceso de redacción de nuestros trabajos" (registro de una experiencia de taller, 22 de mayo de 2018). Como puede verse, estas guías les permitieron ejercer una reflexividad más focalizada y aguzada sobre su propia experiencia corporal y la de otros:

Tomé más conciencia de mi propio cuerpo, sobre todo autobiográficamente. También recordé el olor de varios de los productos para el cuerpo que utilizaba [...] pensando en técnicas que he utilizado para cambiar mi apariencia, percibí con una cierta distancia la ropa en mi piel, el pelo en mi cabeza. Fue un poco como desconectarme de mi cuerpo externo para concentrarme en las técnicas aplicadas a mi cuerpo. Así, me sentí un poco rara y extraña, pero la distancia me sirvió para pensar más objetivamente sobre mi propio cuerpo. (Registro de una experiencia de taller, 27 de marzo de 2018)

En este juego del acercamiento y el distanciamiento, la corporalidad pudo ser registrada en su multiplicidad de sensaciones y percepciones, rompiendo en parte la hegemonía de la vista y el oído:

[...] durante la actividad primera, de explicación del registro etnográfico que tendremos que hacer, la palabra y lo visual (desde el cuello-pecho hacia arriba) fue predominante para lograr el objetivo de "conocernos". Mientras que los otros sentidos y el resto del cuerpo quedaron en segundo plano o directamente "invisibilizados", solo les prestamos atención luego de que apareció como pregunta y consigna concreta desde la docente. (Registro de una experiencia de taller, 17 de abril de 2018)

\section{Algunas modalidades híbridas...}

En este apartado queremos mencionar algunas propuestas que combinan elementos de las modalidades anteriores: la provocación de las materialidades afectantes con la exploración de lo cotidiano en la que se retoma y resignifica una actitud propia del trabajo etnográfico, esta es, la "participación observante" que invita 
a salir a explorar y documentar informaciones de un determinado contexto en el que nos inmergimos. Sin embargo, lo peculiar de nuestra propuesta es que se les pide a los estudiantes y las estudiantes que traigan la "información" al aula, no solo en sus formatos habituales de registros escritos o a lo sumo visuales o audiovisuales, sino apelando especialmente a distintas percepciones y materialidades afectantes. Así, por ejemplo, los estudiantes y las estudiantes son invitados a salir a "percibir" y luego a "recolectar" diversas sensaciones (especialmente táctiles, gustativas, olfativas, sonoras), gestos, situaciones o símbolos, propias de los espacios que habitan cotidianamente (puede ser en la misma universidad donde se dicta la clase, la calle, el barrio) y de la temática que se esté indagando (por ejemplo, dispositivos de sexuación o de racialización, símbolos de poder), y a que traigan alguna materialidad (objetos, movimientos, gestos, sonidos) que evoque aquello que registraron. Una vez que estos materiales-registros son llevados a la clase, se propone reensamblarlos en un montaje performático o instalación; y es este movimiento de descontextualización-recontextualización el que facilita el distanciamiento o la "exotización de lo cotidiano", para tenderle un manto de sospecha y reflexividad crítica.

Un ejemplo de esta estrategia lo realizamos en México, en 2018, en el taller titulado Transmutaciones del ser en el mundo. Hacia la performance-investigación participativa, realizado en el Instituto Nacional de Bellas Artes y la Escuela Nacional de Danzas Folclóricas.

Les pedimos a los/las asistentes que, conformados en grupos, eligieran un espacio de su institución para hacer una exploración y registro del entorno, prestando especial atención a los sentidos táctil, olfativo, gustativo, sonoro y visual, y también a las emociones y recuerdos que les despertara ese lugar. Esta inmersión debía hacerse de manera individual y abierta a todos los sentidos, y luego, se les pedía que eligieran al menos una sensación que les pareciera representativa del lugar. Posteriormente, este registro individual se compartía en el grupo, se conversaba sobre los mismos, y se elegían los más representativos para crear un montaje performático o instalación colectiva. Es decir, el montaje tenía la intención de describir y comunicar cómo es ese espacio vivido y cómo afectaba los cuerpos de los que transitaban o habitaban en él, qué efectos performativos producía. Finalmente, cada grupo mostraba su trabajo y el público debía adivinar de qué espacio se trataba y comentar sus impresiones y afectaciones. (Registro de una experiencia de taller, 12 de noviembre de 2018)

En el contexto de esta institución artística, retomamos la dimensión sensoperceptiva del ser-en-mundo, abordada por la fenomenología de Merleau-Ponty, y destacamos su potencial para pensar nuevas formas de creación, basadas en la exploración de las estésicas cotidianas locales.

Otro ejemplo, proveniente de un ejercicio realizado en 2018, en el seminario de grado Raza, cuerpo y performance de la Escuela de Antropología de la Facultad de Humanidades y Artes de la UNR, buscaba trabajar sobre el concepto 
de "esquema epidérmico-racial" de Frantz Fanon. Manuela Rodriguez, junto a Julia Broguet y Yanina Mennelli, propusieron el siguiente ejercicio:

Les pedimos a los/las estudiantes que recopilaran palabras y/o frases que refirieran a la piel: peyorativos, cariñosos, insultos, sobrenombres; podían ser términos que otros hayan usado para referirse a ellos/ellas, que ellos/ellas hayan usado para designar a otros, o que haya escuchado en situaciones ajenas. Y les pedimos que realizaran un primer ordenamiento de ellas según: - cuáles usaron para referirse a otrxs y cuales les dijeron, en qué contextos y con quiénes; - qué les generaba evocarlos: qué sensaciones, emociones o impresiones relacionaban a esos términos y si los vinculaban a olores, colores, sonidos, texturas.

En la primera parte de la clase, ubicamos a los/las estudiantes en el centro del aula, mientras las docentes quedaban por fuera, generando una especie de círculo "sonoro", recitando frases, textos, poesías, cantando, haciendo sonidos con la boca, partes del cuerpo y con algunos instrumentos percusivos. De a poco, les íbamos pidiendo que larguen la voz, nombrando las frases/palabras que habían recopilado, mientras nosotras sosteníamos ese "colchón sonoro". Luego incluíamos el movimiento y la voz/palabra, y les proponíamos que "muevan las palabras", que las hicieran pasar por el cuerpo, por distintas partes del cuerpo. Luego de un tiempo de esta exploración sonoro/corporal, les pedimos que resuman en una breve secuencia sus palabras/frases afectadas por el movimiento y el sonido y se las mostraran a sus compañerxs. Para finalizar, hicimos una ronda de intercambio y comenzamos a trabajar con algunos fragmentos de los textos teóricos de Fanon y Merleau-Ponty, respecto a los esquemas corporales, de Bhabha sobre estereotipos, y sobre la colonialidad y los cuerpos racializados [sic]. (Registro de una experiencia de taller, 5 de julio de 2018)

En esta propuesta, nuestra intención fue trabajar el colonialismo en su capilaridad, a partir de la instauración de corporalidades inadecuadas señaladas a través del color y la forma de la piel y los cuerpos. Los comentarios sobre esta clase enfatizaron en la posibilidad de rememorar la propia historia desde lo lúdico, y cómo el uso del sonido y del movimiento circular permitía "sensaciones en el cuerpo más genuinas". En especial, aparecieron sensaciones de tristeza, incomodidad, pudor, nostalgia, curiosidad y estremecimiento. Una de las estudiantes comentó: "sentí violencia salir de mi boca cuando repetía lo que alguna vez me habían gritado", y otra nos decía:

[...] la actividad disparó en mí no solo recuerdos sobre insultos peyorativos, frases hechas sobre el color de mi piel, sino también una reflexión acerca de que incluso sobre la negritud recaen estereotipos impuestos con los cuales hay que cumplir al ser de tez más oscura. La violencia racial en algún momento de mi vida me llevó también a querer esconderme de esa racialización. (Registro de una experiencia de taller, 10 de noviembre de 2018)

Como puede apreciarse, la combinación de estas diferentes estrategias metodológicas permitió movilizar, analizar y debatir sobre estos saberes 
encarnados y los diversos procesos de formación de habitus, disciplinamiento, control y violencia que les dieron origen. No obstante, para propiciar la transformación y expansión de estos saberes encarnados hacia nuevos horizontes decoloniales, comenzamos a ensayar otras estrategias metodológicas complementarias, que a continuación caracterizaremos.

\section{Desde los ensayos performáticos colectivos del imaginar-desear}

En estas prácticas, se invita a que los participantes y las participantes diseñen en grupos, ensayos o montajes performáticos en los que propongan una alternativa creativa sobre cómo imaginarían que es posible y deseable transformar una determinada experiencia vivida, la cual fue previamente rememorada o traída a la conciencia mediante la exploración o la afectación producida por las estrategias anteriores. Tal es el caso de las experiencias de disciplinamiento, habitus o performatividades impuestas a nuestras corporalidades en la vida social o de situaciones de violencias, exclusión o discriminación que hemos experimentado, más allá de nuestro desear. Se trata entonces de prácticas que permiten debatir, imaginar y poner en escena deseos transformadores que surjan de estos intercambios colectivos. En este sentido, encontramos que se acercan a las exploraciones de Castro et al. (2019) cuando proponen pedagogías corporales que apelan a lo performativo y operan como "prácticas de re-existencia", en tanto "actos de (trans) formación" tanto del docente como de los estudiantes; y que por ello nos permiten "asumir el aula como espacio de ensayo... donde es posible alterar la forma del acto educativo y a quienes participamos de cuerpo presente en él, pues el ensayo es siempre una zona sensible, inventiva y actuante" (p. 225).

Como ejemplo de esta estrategia, describiremos la propuesta que les hicimos a los participantes y las participantes del taller en el congreso de la Universidad de Medellín para que intervengan y transformen sus "autorretratos" (figura 6).

Primero, se invitó a compartir las propias producciones y a buscar en esos otros trabajos, las resonancias con el propio, agrupándose por afinidad. Una vez formados los grupos, se invitó a que transformaran colectivamente esos autorretratos. Así, por ejemplo, si estos autorretratos respondían al disciplinamiento de los cuerpos en la universidad, se propuso buscar la manera de desdisciplinarlos. Para ello, se invitó a rememorar alguna participación en un contexto festivo, comunitario o popular que recordaran como placentero, y se les pidió que recordaran y registraran cómo estaban sus cuerpos allí, recuperando algunas de las preguntas de la guía analítica del inicio. Con esa nueva información, invitamos a transformar los autorretratos, de manera que ensayemos cómo podría ser la experiencia de nuestros cuerpos en una universidad más plural, decolonial y emancipatoria. 


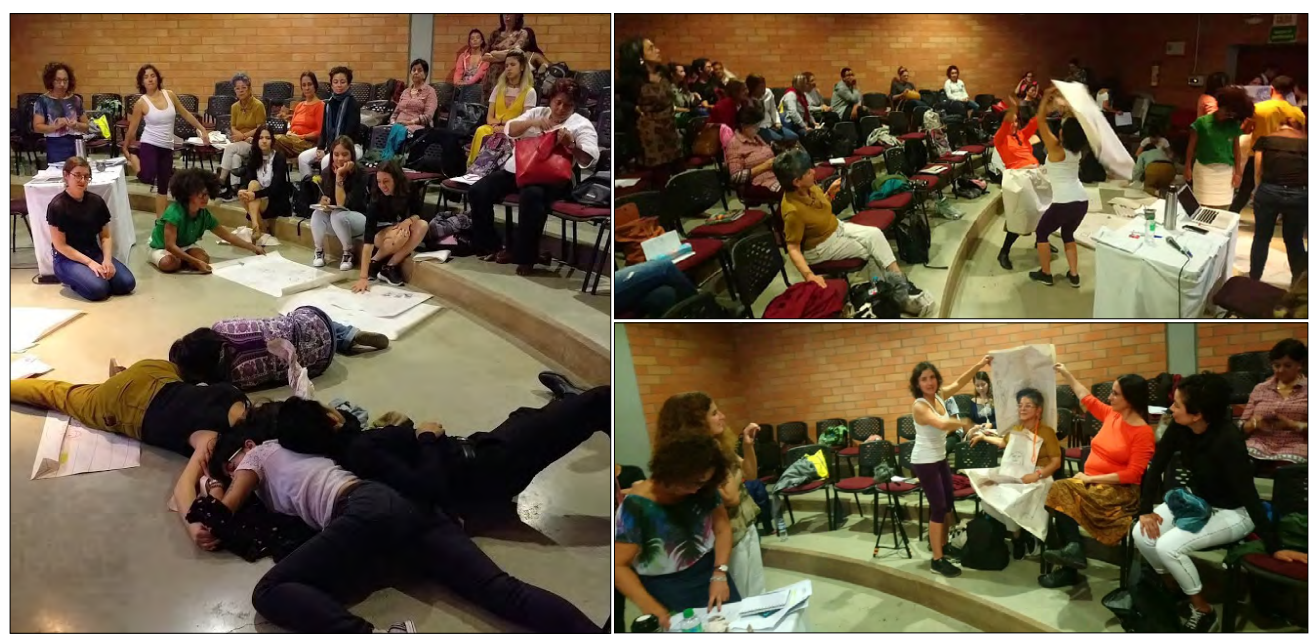

Figura 6. Intervención de los autorretratos en la apertura de la mesa de trabajo Corporalidad, performatividad y prácticas de enseñanza. XI Congreso Internacional de Ciencias Sociales y Humanas, Facultad de Ciencias Sociales y Humanas, Universidad de Medellín

Fuente: Hilderman Cardona-Rodas, archivo personal, 2019.

Esta modalidad se vincula genealógicamente a diferentes prácticas y autores. Por un lado, a la noción de "inédito viable" en la pedagogía de Freire, en tanto invita a la reflexión crítica pero también a la imaginación y proyección de una acción transformadora frente a una situación de opresión. Según este autor:

[...] el inédito viable es algo que el sueño utópico sabe que existe pero que sólo se conseguirá por la praxis libertadora que puede pasar por la teoría de la acción dialógica (...) Así, cuando los seres conscientes quieren, reflexionan y actúan para derribar las situaciones límite que los obligan como a casi todos y todas a ser menos, lo "inédito viable" ya no es él mismo, sino su concreción en lo que antes tenía de no viable [sic]. (Freire, 1999, p. 195)

Esta dimensión de la acción dialógica, no solo en palabras sino también en cuerpos actuantes, es la que justamente remarca el teatro del oprimido de Boal, continuador en el campo teatral de las propuestas de Freire y que ha sido otra de nuestras influencias. El autor aboga para que el público pase de su habitual rol de espectador al de "actor participante" e "inventen un nuevo mundo" en la ficción teatral, pero con la intención de que ese ejercicio "estimule el deseo de cambiar el mundo" en la realidad social (Boal, 2001, pp. 84-85). Así, al asumir un rol protagónico en la acción, encarnando performances transformadoras, el "espectador [...] ensaya soluciones, debate proyectos de cambio, en resumen, se entrena para la acción real", por ello, dirá también, esta modalidad participativa se constituye en un "ensayo de la revolución" (Boal, 1989, pp. 17, 25). Cabe agregar que, en nuestra aproximación y transformación de esta metodología, han sido 
fundamentales los aportes de otra investigadora de nuestro equipo, Lucrecia Greco, quien viene indagando en el teatro del oprimido y otras metodologías provenientes del campo de la educación popular y los movimientos sociales.

Dentro de este campo, las elaboraciones del psicodrama y el sociodrama —iniciado por el rumano Moreno en la década de 1920, y con un gran desarrollo posterior en Argentina, especialmente en su articulación con el psicoanálisis y las teorías de Deleuze y Guattari- son otras influencias que podemos reconocer. Causa especial interés la estrategia de la "multiplicación dramática" de las escenas-conflictos individuales, propuesta por Pavlovsky (2000) y otros autores, en la que "el grupo creando otros espacio-tiempos, desterritorializa la historia a partir de una o varias líneas de fuga que escapan del contorno de la versión dramática inicial" (p. 47).

Por último, y como ya adelantamos, otro campo de experiencias que nos ha inspirado emerge de nuestras investigaciones sobre prácticas culturales provenientes de pueblos indígenas y afrodescendientes. Así, podríamos decir que "lo inédito viable" muchas veces emergió para nosotras del acercamiento a esos otros modos de existencia. No obstante, también advertimos la necesidad de una mirada crítica que nos alerte frente a las tendencias primitivistas y exotizantes de la colonialidad (que incluso atravesaron a muchas de las vanguardias artísticas, tanto europeas como latinoamericanas), que "otrificaron" y "escencializaron", a la manera de un espejo distorsionado, lo que serían prácticas otras. En contraste, la interculturalidad se propone como un horizonte de comunicabilidad que abogue, desde una perspectiva poscolonial, por la hibridez y la posibilidad de combinar diversos modos de saber-hacer. Pero también, y principalmente, como un modo de alertarnos sobre nuestros propios etnocentrismos para intentar aprender diversos modos de existencia y de producción del saber que desestabilizan lo que creíamos aprendido; un movimiento muy propio del trabajo de campo etnográfico.

\section{Conclusiones}

Para concluir, compartiremos algunas certezas y también sospechas en relación con el potencial trasformador de estas prácticas. En lo que refiere a nuestras actuales certezas, consideramos que cuanto más abiertos estemos a ensayar articulaciones entre modalidades didácticas que apelen al impacto senso-perceptivo y afectivo de las materialidades afectantes, de las propias genealogías (individuales, intersubjetivas y grupales), de la reflexividad analítica y de los ensayos performáticos colectivos del imaginar-desear, mayor será la eficacia de estas prácticas para movilizar procesos de reflexión sobre los saberes encarnados. Asimismo, se pueden dar micropolíticas de agenciamiento que propicien 
su transformación y expansión en un horizonte decolonial intercultural. Las siguientes reflexiones de los estudiantes y las estudiantes dan cuenta de los efectos epistemológicos y políticos de estas estrategias metodológicas, sobre todo cuando se comparan con los formatos pedagógicos tradicionales.

[...] tener que pensar específicamente cómo me afectan estos contenidos en mi propia experiencia de vida facilita hacer el link con lo que se expuso más tradicionalmente...

en la clase con la pedagogía tradicional mi atención está dirigida al profesor, pero en los ejercicios se dirige a mí misma y con la atención, la percepción sube.

en el tradicional, predomina lo verbal, lo mental y las relaciones de uno a uno (la profe con el grupo, la profe con un estudiante, un estudiante con la profe). En cambio, cuando ponemos en movimiento el cuerpo, comenzamos a desarrollar más vínculos entre nosotros, se abre el campo a lo grupal y a otro tipo de percepción, más sensible y vincular, más profunda. (Registro de una experiencia de taller, 27 de marzo de 2018)

Asimismo, la inclusión de los otros sentidos, además de la vista y el oído, implica la apertura hacia el placer, la comunión y la conexión con las otras personas:

$[\ldots]$ creo que es una de las pocas experiencias que recordaré que en la facultad nos hayan hecho experimentar la teoría a través de un sentido que no sea el visual. Incluir el tacto, el oído, el olfato y el gusto permite aproximar y volver a acercar el placer a la experiencia pedagógica.

el hecho de poder sentarse en el piso, comer, beber, fue como una comunión más amena, en la cual se respiraba más libertad y menos estructura.

la posibilidad de presentar comida y comer libremente a través de la clase es sin duda una agradable diferencia. La comida favorece el intercambio y la confraternización. Ir hacia la comida desdibuja el estatismo de la recepción desde el pupitre y dinamiza. Nuevas ubicaciones reconfiguran el espacio y la forma de intercambio. Las nociones teóricas se desdibujan un poco, pero el recuerdo de la clase permanece en el tiempo, mes y medio después... la conexión grupal en el aula ayuda a elaborar pensamiento colectivo. (Registro de una experiencia de taller, 12 de abril de 2017)

También recientemente, Cardona y Citro (2019) han analizado cómo estas metodologías, especialmente en la fase de los "ensayos performáticos colectivos del imaginar-desear" suelen promover el contacto corporal y los lazos intersubjetivos entre los estudiantes y las estudiantes a partir de una tactilidad extendida o sentido háptico. En suma, a partir de estas reflexiones, se evidencia cómo estas prácticas nos acercan a aquellas "pedagogías de la vincularidad" basadas en la empatía sensible, la dialogicidad y la reciprocidad. Y como sostuvimos, estas son fundamentales para desmontar las pedagogías de la violencia y el disciplinamiento de la modernidad/colonialidad y favorecer, en cambio, la emergencia de agenciamientos colectivos. 
Finalmente, en lo que respecta a nuestras sospechas, parafraseando a Deleuze y Guattari (1994), creemos que debemos tener paciencia y ser prudentes en relación con nuestro entusiasmo sobre los efectos performativos de estas prácticas. Uno de los corolarios que se desprende de las teorías de la performatividad es que este tipo de ensayos creativos que juegan a transformar nuestras performatividades sociales disciplinantes y a ensayar lo "inédito viable", a multiplicar las escenas de lo posible, o a experimentar líneas de fuga, solo podrán ser eficaces si se reiteran durante un lapso considerable de tiempo y se repican y multiplican en diferentes ámbitos de la vida social. Por tanto, la transformación micropolítica de cada acto educativo particular, si bien es necesaria y tiene efectos intersubjetivos, no puede desligarse de las luchas políticas más amplias con relación a las instituciones y los sistemas educativos (locales, nacionales y globales), así como a los condicionamientos económico-políticos en los que estos han operado.

\section{Referencias}

Artaud, A. (2005). El arte y la muerte. Caja Negra editora.

Aisenstein, Á. (2006). Cuerpo, escuela y pedagogía. Argentina, siglos XIX y XX. En Á. Aisenstein y P. Scharagrodsky (eds), Tras las huellas de la educación física escolar argentina. Cuerpo, género y pedagogía.1880-1950 (pp. 19-47). Prometeo.

Aschieri, P. (2013). Subjetividad en movimiento: Reapropiaciones de la danza butoh en Argentina [tesis doctoral, Universidad de Buenos Aires] Repositorio Institucional, Facultad de Filosofía y Letras, Universidad de Buenos Aires. http://repositorio.filo.uba.ar/handle/filodigital/1645

Boal, A. (1989). Teatro del Oprimido: teoría y práctica. Nueva Imagen.

Bravin, C. (2013). Cuerpo y subjetividad en el campo de la sociología de la educación: conquistas y nuevos desafíos. En C. Kaplan (ed.), Culturas estudiantiles. Sociología de los vínculos en la escuela (pp. 253-274). Miño y Dávila Editores.

Butler, J. (1999). El género en disputa: el feminismo y la subversión de la identidad. Paidós.

Castro, J., Ciodaro, M. y Duran-Salvadó, N. (2019). Prácticas de re-existencia: pedagogías corporales en la docencia universitaria. Revista mexicana de investigación educativa, 24(80), 223-245.

Cardona-Rodas, H. y Citro, S. (2019, 22-25 de julio). Cuerpo-placer-dolor: hacia una antropología del acontecimiento sensible [ponencia]. XIII reunión de antropología del Mercosur, Porto Alegre, Brasil.

Citro, S. (1997). Cuerpos festivo-rituales. Un abordaje desde el rock [tesis de pregrado, Universidad de Buenos Aires]. Repositorio Institucional, Facultad de Filosofía y Letras, Universidad de Buenos Aires.

Citro, S. (2003). Cuerpos significantes. Una etnografía dialéctica con los toba takshik [tesis doctoral, Universidad de Buenos Aires]. Repositorio Institucional, Facultad de Filosofía y Letras, Universidad de Buenos Aires. http://repositorio.filo.uba.ar/handle/filodigital/1250

Citro, S. (2009). Cuerpos significantes. Travesías de una etnografía dialéctica. Editorial Biblos. 
Citro, S. y Equipo de Antropología del Cuerpo y la Performance. (2015, 7-10 de octubre). Cuerpo, performatividad y poder en las prácticas académicas: Un ensayo de performance-investigación [ponencia]. IV Congreso de la Asociación Latinoamericana de Antropología, Ciudad de México, México.

Citro, S. (2018). Taller de performance-investigación. Indagaciones colectivas de y desde los cuerpos. En A. Reyes, J. Piovani y E. Potaschner (coords.), La Investigación social y su práctica. Aportes latinoamericanos a los debates metodológicos de las Ciencias Sociales (pp. 271-306). Clacso y Editorial Teseo.

Citro, S. (2019, 18 de enero). Corporalidad y performance en las prácticas educativas. Matrices para un horizonte decolonial [lección inaugural de la Maestría en Educación, Facultad de Ciencias Sociales y Humanas]. Universidad de Medellín.

Deleuze, G. y Guattari, F. (1994) Mil mesetas. Capitalismo y esquizofrenia. Pre-textos.

Dussel, E. (2000). Europa, modernidad y eurocentrismo. En E. Lander (comp.), La colonialidad del saber: eurocentrismo y ciencias sociales. Perspectivas latinoamericanas (pp. 41-53). Clacso.

Elías, N. (1993). El proceso de civilización. Fondo de Cultura Económica.

Fanon, F. (2009). Piel negra, máscaras blancas. Ediciones Akal.

Freire, P. (1999). Pedagogía del oprimido. Siglo XXI

Foucault, M. (1987). Vigilar y castigar. Siglo XXI.

Gallo, L. (2017). Una didáctica performativa para educar (desde) el cuerpo. Revista brasileira de ciências do esporte, 39(2), 199-205. https://doi.org/10.1016/j.rbce.2016.09.002

Geertz, C. (1987). La interpretación de las culturas. Gedisa.

Goofman, E. (1970). Ritual de la interacción. Tiempo Contemporáneo.

Ingold, T. (2012). Toward an Ecology of Materials. Annual Review of Anthropology, 41, 427-42.

Laban, R. (1958). El dominio del movimiento. Fundamentos.

Lander, E. (2005). Ciencias sociales: saberes coloniales y eurocéntricos. En E. Lander (comp.), La colonialidad del saber: eurocentrismo y ciencias sociales. Perspectivas latinoamericanas (pp.11-40). Clacso.

Latour, B. (2005). Reassembling the social: na introduction to actor-network theory. Oxford University Press.

Merleau-Ponty, M. (1993). Fenomenología de la percepción. Planeta.

Mignolo, W. (2003). Historias locales/Diseños globales: Colonialidad, conocimientos subalternos y pensamiento fronterizo. Ediciones Akal.

Milstein, D. y Méndes, H. (1999). La escuela en el cuerpo. Estudios sobre el orden escolar y la construcción social de los alumnos en escuelas primarias. Miño y Dávila.

Morgade, G. y Alonso, G. (comp.). (2008). Cuerpos y sexualidades en la escuela. Paidós.

Nietzsche, F. (2000). La voluntad de poder. EDAF.

Pavlovsky, E. (2000). Lo Grupal: Devenires historias. Búsqueda de Ayllu.

Quijano, A. (2000). Colonialidad del poder, eurocentrismo y América Latina. En. E. Lander (comp.), La colonialidad del saber: eurocentrismo y ciencias sociales. Perspectivas Latinoamericanas. Clacso. 
Rivera Cusicanqui, S. (2015). Sociología de la imagen. Tinta Limón.

Segato, R. (2018). Contrapedagogias de la crueldad. Prometeo.

Varea, V. y Galak, E. (Eds.). (2013). Cuerpo y Educación Física. Perspectivas latinoamericanas para pensar la educación de los cuerpos. Biblos.

Walsh, C. (2008). Interculturalidad crítica, pedagogía decolonial. En W. Villa y A. Grueso (comp.) Diversidad, interculturalidad y construcción de ciudad. Universidad Pedagógica Nacional/Alcaldía Mayor de Bogotá. 